ARTICLE

\title{
Synthesis of chiral anti-1,2-diamine derivatives through copper(I)-catalyzed asymmetric $\alpha$-addition of ketimines to aldimines
}

\author{
Xu-Cheng Gan ${ }^{1,2,3}$, Cheng-Yuan Zhang ${ }^{2,3}$, Feng Zhong ${ }^{2,3}$, Ping Tian (1D) ${ }^{1 凶}$ \& Liang Yin (1) ${ }^{1,2 凶}$
}

Chiral 1,2-diamines serve as not only common structure units in bioactive molecules but also useful ligands for a range of catalytic asymmetric reactions. Here, we report a method to access anti-1,2-diamine derivatives. By means of the electron-withdrawing nature of 2- or 4nitro-phenyl group, a copper(I)-catalyzed asymmetric $\alpha$-addition of ketimines derived from trifluoroacetophenone and 2- or 4- $\mathrm{NO}_{2}$-benzylamines to aldimines is achieved, which affords a series of chiral anti-1,2-diamine derivatives in moderate to high yields with moderate to high diastereoselectivity and high to excellent enantioselectivity. Aromatic aldimines, heteroaromatic aldimines, and aliphatic aldimines serve as suitable substrates. The nitro group is demonstrated as a synthetical handle by several transformations, including a particularly interesting $\mathrm{Fe}(\mathrm{acac})_{3}$-catalyzed radical hydroamination with a trisubstituted olefin. Moreover, the aryl amine moiety obtained by the reduction of the nitro group serves as a synthetically versatile group, which leads to the generation of several functional groups by the powerful Sandmeyer reaction, such as $-\mathrm{OH},-\mathrm{Br},-\mathrm{CF}_{3}$, and $-\mathrm{BPin}$.

\footnotetext{
${ }^{1}$ The Research Center of Chiral Drugs, Innovation Research Institute of Traditional Chinese Medicine and China-Thailand Joint Research Institute of Natural Medicine, Shanghai University of Traditional Chinese Medicine, 201203 Shanghai, China. ${ }^{2}$ CAS Key Laboratory of Synthetic Chemistry of Natural Substances, Center for Excellence in Molecular Synthesis, Shanghai Institute of Organic Chemistry, University of Chinese Academy of Sciences, Chinese Academy of Sciences, 200032 Shanghai, China. ${ }^{3}$ These authors contributed equally: Xu-Cheng Gan, Cheng-Yuan Zhang, Feng Zhong.

凶email: tianping@shutcm.edu.cn; liangyin@sioc.ac.cn
} 
C hiral 1,2-diamines have been identified as one of the most important structural motifs in bioactive natural products and pharmaceutical compounds ${ }^{1-4}$. Moreover, they served as both powerful ligands in transition metal-catalyzed asymmetric reaction and efficient chiral organocatalysts ${ }^{5-8}$. Therefore, various methods have been developed for their asymmetric synthesis ${ }^{1-4}$. Reported synthetic methods could be divided into three types, transformations with preformed diamine skeleton, transformations with carbon-nitrogen bond formation, and transformations with carbon-carbon bond formation. In the third type, a carbon atom containing an $\mathrm{N}$-based functional group, such as nitro ${ }^{9}$, isocyanide $^{10-13}$, isothiocyanato ${ }^{14,15}$, or ketimine $^{16}$ was usually employed as the pronucleophile in addition to aldimines. In the case of ketimine, a 2 -azaallyl anion ${ }^{16}$ was generated upon the deprotonation with a base, which would exhibit two pathways toward electrophiles, $\alpha$-addition and $\alpha^{\prime}$-addition (Fig. 1a).

Usually, a second functional group such as ester ${ }^{17-21}$, nitrile 22,23 , or phosphate ${ }^{18,24}$ was required to stabilize the 2-azaallyl anion $\left(\mathrm{R}^{1}=\mathrm{CO}_{2} \mathrm{R}, \mathrm{CN}\right.$, or $\left.\mathrm{P}(\mathrm{O})(\mathrm{OR})_{2}\right)$. Furthermore, the introduction of a strong electron-withdrawing group on the a-position of ketimine would lower $\mathrm{p} K_{\mathrm{a}}$ value of the $\alpha$-protons and thus enable a facile proton-transfer $\alpha$-addition to aldimines, which would produce chiral 1,2-diamine derivatives in the presence of a chiral catalyst. In 2008, Hou, Wu and co-workers disclosed an interesting catalytic asymmetric Mannich reaction of $N$-(diphenylmethylene)glycine methyl ester with high enantioselectivity ${ }^{17}$ (Fig. 1b). By changing the electronic property on the ligand (FOXAP), both syn- and anti1,2-diamine derivatives were synthesized in high diastereoselectivity. Moreover, Zhao group uncovered a powerful biomimetic asymmetric Mannich reaction of tert-butyl glycine hydrochloride via carbonyl catalysis, which afforded chiral anti-1,2-diamine derivatives in excellent diastereo- and enantioselectivity ${ }^{21}$.

Except for stabilized 2-azaallyl anion, semi-stabilized 2-azaallyl anion $\left(\mathrm{R}^{1}=\right.$ aryl $)$ and nonstabilized 2 -azaallyl anion $\left(\mathrm{R}^{1}=\mathrm{H}\right.$ or alkyl) were also employed as nucleophiles in the $\alpha$-addition to aldimines $^{16}$. As a breakthrough in this field, Kobayashi group disclosed a $\mathrm{KO}^{t} \mathrm{Bu}-18$-crown-6-catalyzed Mannich-type reaction of (9-fluorenylidene)aminoalkanes and Dpp-aldimines ${ }^{25}$. However, a catalytic asymmetric version afforded a chiral syn-1,2diamine derivative in $74 \%$ ee. Although Reddy group developed a diastereoselective version by using Davis-Ellman's imines in 2018 (ref. ${ }^{26}$ ), a catalytic asymmetric reaction has rarely been achieved. In the same year, Malcolmson's group reported a powerful reductive coupling of azadienes with aldimines and ketimines, which afforded anti-1,2-diamine derivatives in excellent diastereo- and enantioselectivities ${ }^{27}$. In this beautiful reaction, a catalytic amount of nonstabilized 2-azaallyl anions were generated by the reduction of azadienes with (Ph-BPE) $\mathrm{CuH}$.

a

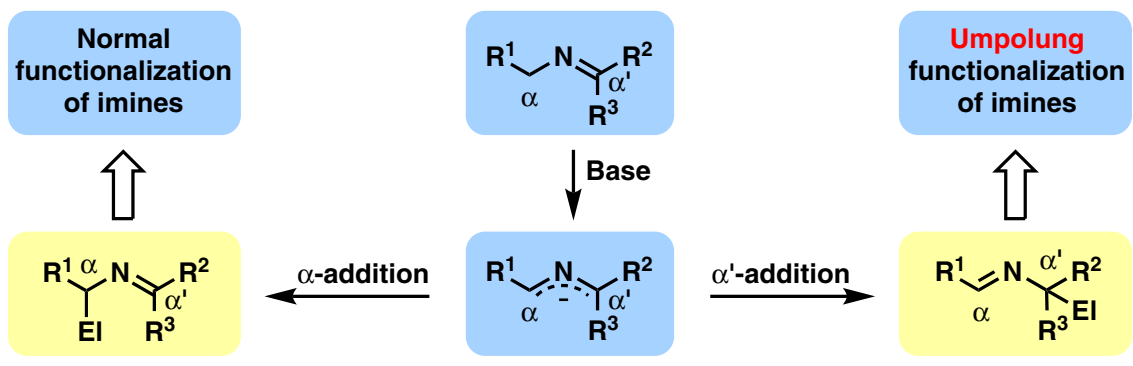

b

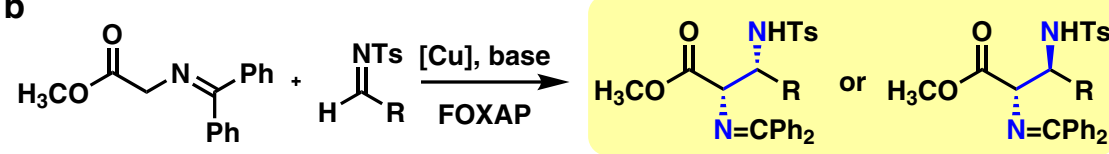

C<smiles>[R]C=CC=O</smiles>

d<smiles>FC(F)(F)C(=NC[Ga])c1ccccc1</smiles><smiles>[R]C=[N+](C)OC</smiles>

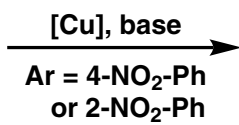<smiles>[R]C(NC(=O)OCc1ccccc1)C(Br)=NC(=O)c1ccccc1</smiles>

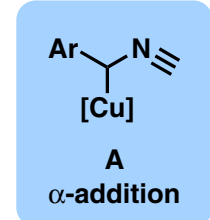

Studied

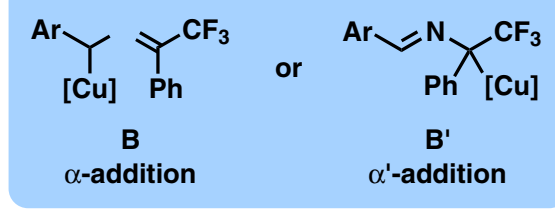

Not studied
Potential problems:

- Regioselectivity?

- Enantioselectivity?

- Diastereoselectivity?

- Transformation of the nitro group?

Fig. 1 Prior arts and our work in the catalytic asymmetric reactions with 2-azaallyl anions. a Regioselectivity in the nucleophilic addition of 2-azaallyl anions. b Reported catalytic asymmetric $\alpha$-addition by Hou and Wu. c Reported catalytic asymmetric $\alpha^{\prime}$-addition (umpolung addition) by Deng. $\mathbf{d}$ Our work: synthesis of 1,2-diamines through copper(I)-catalyzed $\alpha$-addition. 
The $\alpha^{\prime}$-addition of 2-azaallyl anion is called as a umpolung addition of imine as imine usually serves as electrophile toward various nucleophiles ${ }^{28}$, which provides accesses to new structures and new substitution patterns ${ }^{29-39}$. In 2015, Deng group uncovered an admiring catalytic asymmetric umpolung reaction of ketimines derived from trifluoroacetophenone and $4-\mathrm{NO}_{2}-$ benzylamines and $\alpha, \beta$-unsaturated aldehydes ${ }^{29}$ (Fig. 1c). In the presence of a powerful organocatalyst derived from cinchona alkaloid, the generated 2-azaallyl anions from ketimines via deprotonation favored $\alpha^{\prime}$-addition to $\alpha, \beta$-unsaturated aldehydes (1,4-conjugate addition). However, $\boldsymbol{\alpha}$-addition of such 2 -azaallyl anions has been much less achieved in asymmetric catalysis. In 2015, Shibasaki and Kumagai proposed a benzyl copper(I) species A, which reacted with aldimines to afford chiral 1,2-diarylethylenediamine derivatives through $a$-addtion ${ }^{13}$. Therefore, it is envisioned that a benzyl copper(I) species B will be generated through the deprotonation of the ketimine with a base in the presence of a copper(I) complex, which may form an equilibrium with another benzyl copper(I) species B' (Fig. 1d). Species B will lead to $\alpha$-addition, while species $B^{\prime}$ will lead to $\alpha^{\prime}$-addition. Significant steric hindrances from both the bulky copper (I)-bisphosphine complex and the congested $\alpha^{\prime}$-position bearing $\mathrm{Ph}$ and $\mathrm{CF}_{3}$ exist in $\alpha^{\prime}$-addition, and thus $\alpha^{\prime}$-addition is disfavored. Obviously, $\alpha$-addition of the benzyl copper(I) species to aldimines will produce chiral 1,2-diamine derivatives. Moreover, it is well known that the nitro group serves as a versatile functional group in organic synthesis ${ }^{40}$. By reducing the nitro group to amino group, Sandmeyer reaction ${ }^{41}$ will allow facile preparation of more chiral 1,2-diamines containing a variety of other functional groups.

Here, we show the catalytic asymmetric a-addition of ketimines derived from trifluoroacetophenone and 2- or $4-\mathrm{NO}_{2}$ benzylamines to aldimines, which furnishes a series of anti-1,2diamine derivatives in moderate-to-high yields with moderate-tohigh diastereoselectivity and high-to-excellent enantioselectivity. The nitro group in the products is demonstrated as a synthetic handle to afford amine and nitrone. Moreover, the produced arylamine serves as an excellent substrate for synthetically powerful Sandmeyer reaction to afford arene, phenol, arylbromide, trifluoroarene, or arylboronate in good yield.

\section{Results}

Condition optimization. First of all, the reaction between ketimine $1 \mathrm{a}$ and $\mathrm{N}$-Boc-aldimine $2 \mathrm{a}$ was performed in the presence of $5 \mathrm{~mol} \% \mathrm{Cu}\left(\mathrm{CH}_{3} \mathrm{CN}\right)_{4} \mathrm{PF}_{6}, 5 \mathrm{~mol} \%(R)$-BINAP, and $5 \mathrm{~mol} \%$ Barton's Base (Table 1, entry 1). The addition proceeded smoothly to afford product $3 \mathrm{aa}$ in $48 \%$ yield with $17 \%$ ee. By screening of commercially available bisphosphine ligands, $\left(R, R_{P}\right)$ TANIAPHOS was found to be the best in term of enantioselectivity (entries 2-8). Lowering the reaction temperature to $-30^{\circ} \mathrm{C}$ resulted in $96 \%$ ee (entry 9). Other organic bases, such as TMG and $\mathrm{Et}_{3} \mathrm{~N}$, also worked very well to catalyze the reaction with higher yields and maintained enantioselectivity (entry 10-11). Mesitylcopper ${ }^{42}-\left(R, R_{P}\right)$-TANIAPHOS was used to replace the combination of $\mathrm{Cu}\left(\mathrm{CH}_{3} \mathrm{CN}\right)_{4} \mathrm{PF}_{6}-\left(R, R_{P}\right)$-TANIAPHOS-organic base, which resulted in the same reaction efficiency (entry 12). Changing the solvent from THF to DME led to a slightly increased yield (entry 13). Other solvents (including ${ }^{n}$ octane, toluene, mesitylene, $\mathrm{PhCF}_{3}$, and $\mathrm{DCM}$ ) were also tested without any better results observed (for the details, see Supplementary Table 1). The conditions shown in entry 13 were selected as the optimized reaction conditions due to the easy manipulation with mesitylcopper and the highest yield. Without mesitylcopper complex, the reaction did not proceed at all at room temperature (entry 14). Except for $N$-Boc aldimine 2a, other aldimines derivated from benzaldehyde, such as $\mathrm{N}$-Cbz aldimine, $\mathrm{N}$-Ts aldimine, $N$-2-thiophenesulfonyl aldimine, and $N-\mathrm{P}(\mathrm{S}) \mathrm{Ph}_{2}$ aldimine were also evaluated under the reaction conditions showed in entry 13. However, no superior results were obtained (for the details, see Supplementary Table 2). Both $\mathrm{N}$-Ts aldimine and $\mathrm{N}$-2thiophenesulfonyl aldimine afforded the corresponding products without asymmetric induction. The reaction with $\mathrm{N}-\mathrm{Cbz}$ aldimine and $N-P(S) \mathrm{Ph}_{2}$ aldimine led to much worse yields and enantioselectivity.

Substrate scope. Under the optimized reaction conditions, the substrate scope of aldimines was investigated (Fig. 2). As for the aromatic aldimines containing a para-substituent, both electrondonating groups and electro-withdrawing groups were well tolerated with the corresponding products generated in $7 / 1$ to $>20 / 1$ $\mathrm{dr}$ and $81 \%$ to $98 \%$ ee (3aa-3am). However, aromatic aldimines with electron-withdrawing groups afforded lower yields. Both the aromatic aldimines containing an ortho-substituent and the aromatic aldimines containing a meta-substituent were competent substrates too (3an-3aq). Moreover, both 1-naphthyl aldimine and 2-naphthyl aldimine were well applicable to the present reaction protocol (3ar-3as). The reactions of two heteroaromatic aldimines, containing 2-thienyl and $\mathrm{N}$-Boc-3-indolyl, also worked very well (3at-3au). It should be mentioned that the diastereoselectivity was moderate in several cases (3ag, 3ao, and 3at).

Then, aliphatic aldimines were examined. Aldimines with a cycloalkyl substituent were found as satisfactory substrates too (3av-3aw). In the cases of $\alpha$-branched aldimine $(2 x)$ and $\beta$ branched aldimine (2y), the reactions were performed in THF at room temperature in the presence of $10 \mathrm{~mol} \%$ mesitylcopper and $10 \mathrm{~mol} \% \quad\left(R, R_{P}\right)$-TANIAPHOS. Products (3ax-3ay) were obtained in moderate yields with moderate diastereo- and high enantioselectivities. The diastereoselectivity in these cases was moderate possibly due to the smaller differences of both steric hindrance and electronic nature between an alkyl and the hydrogen atom. The absolute configurations of the two stereogenic carbon centers in 3ai were determined by X-ray analysis of its single crystals. The absolute configurations of other products were deduced by analogy.

A simple study of ketimines was performed, as shown in Fig. 3. In order to get better results, the reaction conditions (including reaction temperature, and solvent) were slightly changed. Generally speaking, lower reaction temperature favors higher enantioselectivity, while higher reaction temperature favors higher yield. In many cases, THF was a better solvent than DME, which led to higher enantioselectivity at higher reaction temperature than $-30^{\circ} \mathrm{C}$. As shown in Fig. 3, as for 4-nitrobenzyl imines, a substituent, such as methyl, fluorine, and chlorine was successfully tolerated at the 2-positon (3ba, 3ca, and $3 \mathrm{da}$ ). However, with the increasing of steric hindrance of the substituent, the diastereoselectivity decreased. Furthermore, a substituent, such as methyl, methoxyl, and thiophenyl, could be introduced at the 3-position with high diastereo- and enantioselectivities observed (3ea, 3fa, and 3ga). At last, 2-nitrobenzyl imine $1 \mathrm{~h}$ was investigated, which was transformed to product 3 ha in $75 \%$ yield with $4 / 1 \mathrm{dr}$ and $91 \%$ ee. Similar reaction efficiency was observed in the reactions of imines $3 \mathrm{i}$ and $3 \mathrm{j}$. It should be pointed out that the reactions of 2-nitrobenzyl imines proceeded in moderate diastereoselectivity. The absolute configurations of $3 \mathrm{ba}-3 \mathrm{ja}$ were assumed according to the stereostructure of 3ai. Except for the nitro group, other electronwithdrawing groups, such as $4-\mathrm{COOMe}, 4-\mathrm{CF}_{3}, 4-\mathrm{P}(\mathrm{O}) \mathrm{Ph}_{2}, 4$ $\mathrm{CN}$, and $4-\mathrm{SO}_{2} \mathrm{CF}_{3}$ were also introduced into the ketimines. However, even at room temperature, the reaction with 4COOMe- $\mathrm{Ph}$, 4- $\mathrm{CF}_{3}-\mathrm{Ph}, 4-\mathrm{P}(\mathrm{O}) \mathrm{Ph}_{2}-\mathrm{Ph}$, and $4-\mathrm{CN}-\mathrm{Ph}$ proceeded 
Table 1 Optimization of reaction conditions ${ }^{\mathrm{a}}$.

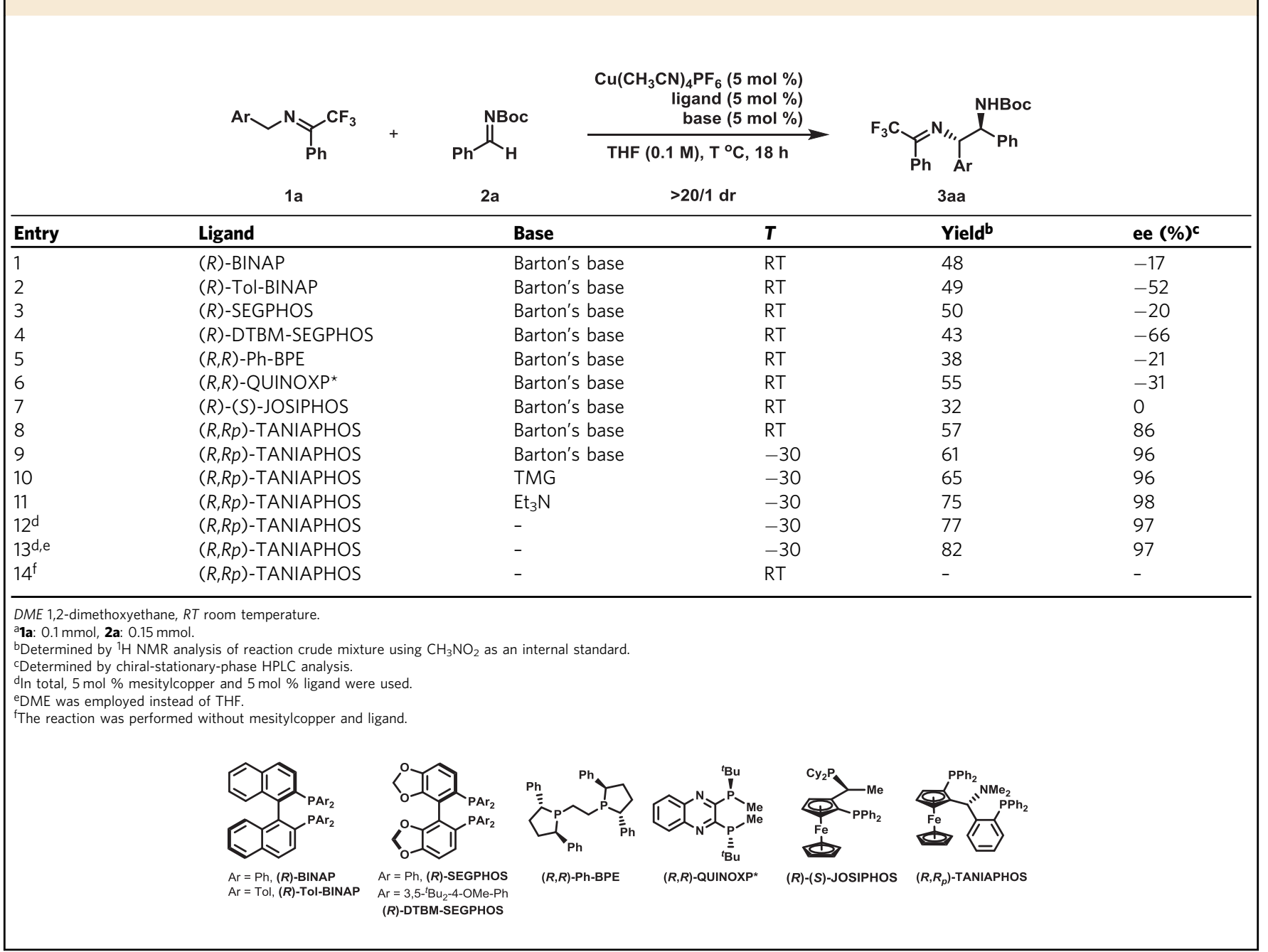

in unsatisfactory results, indicating less efficient deprotonation process. The ketimine-bearing $4-\mathrm{SO}_{2} \mathrm{CF}_{3}$ was a suitable substrate, which reacted with aldimine $2 \mathrm{a}$ to give the corresponding product in $53 \%$ yield with $91 \%$ ee (for the details, see Supplementary Table 3).

Gram-scale reaction and transformation. A gram-scale preparation of 3 aa was achieved successfully with $2 \mathrm{~mol} \%$ mesitylcopper and $2 \mathrm{~mol} \%\left(R, R_{P}\right)$-TANIAPHOS at $-20^{\circ} \mathrm{C}$ as shown in Fig. 4, which afforded 1.15 gram 3 aa in $75 \%$ yield with $>20 / 1 \mathrm{dr}$ and $96 \%$ ee. The transformation of the nitro group to the nitrone group was easily achieved without touching both the imine moiety and the N-Boc moiety. Nitrone 4 was generated in $77 \%$ yield by following a reported reaction procedure ${ }^{43}$, which potentially might serve as a versatile intermediate in organic synthesis. The cleavage of both $\mathrm{C}=\mathrm{N}$ moiety and $\mathrm{N}$-Boc moiety was carried out in $12 \mathrm{M} \mathrm{HCl}$ in $\mathrm{MeOH}$ to give the desired anti1,2-diamine, which was protected with $\mathrm{TsCl}$ to deliver 5 in $81 \%$ yield for two steps. The nitro group in 5 was easily reduced to an amine group (6) in $98 \%$ yield in the presence of $\mathrm{Pd} / \mathrm{C}$ under $1 \mathrm{~atm}$ $\mathrm{H}_{2}$. Interestingly, 5 underwent a $\mathrm{Fe}(\mathrm{acac})_{3}$-catalyzed radical hydroamination with 3-methylbut-3-en-1-ol to furnish a-tertiary amine 7 in $59 \%$ yield $^{44}$.

Transformations of aromatic amine 6 were performed by means of synthetically powerful Sandmeyer reaction ${ }^{41}$ (Fig. 5). The removal of the $\mathrm{NH}_{2}$ group was carried out by means of the traditional Sandmeyer reaction conditions, which delivered 1,2diaryldiamine 8 in $80 \%$ yield. The conversion of arylamine 6 to phenol 9 was achieved in $73 \%$ yield. The preparation of arylbromide 10 was also accomplished in $75 \%$ yield. The deaminative trifluoromethylation was carried out to give 11 in $54 \%$ yield by following a newly reported procedure ${ }^{45}$. The conversion of arylamine 6 to arylboronate 12 was achieved in $66 \%$ yield $^{46}$. More interestingly, by following a powerful reaction ${ }^{47}$, aryl azide 13 was synthesized from 6 in $93 \%$ yield. Evidently, compounds 9, 10, 12, and 13 would allow further easy structure elaboration.

\section{Discussion}

In conclusion, we developed a copper(I)-catalyzed asymmetric $\alpha$ addition of ketimines derived from trifluoroacetophenone and 2or $4-\mathrm{NO}_{2}$-benzylamines to $\mathrm{N}$-Boc-aldimines. A series of chiral anti-1,2-diamine derivatives were generated in moderate-to-high yields with moderate-to-high diastereoselectivity and high-toexcellent enantioselectivity. The reaction enjoyed a broad substrate scope of aldimines. The nitro group in the products served as a synthetic handle to facilitate further structure elaboration. Furthermore, the arylamine generated by the reduction of the nitro group was an excellent substrate for the synthetically powerful Sandmeyer reaction, which was transformed to arene, phenol, arylbromide, trifluoroarene, and arylboronate. More interestingly, the preparation of aryl azide was efficiently 


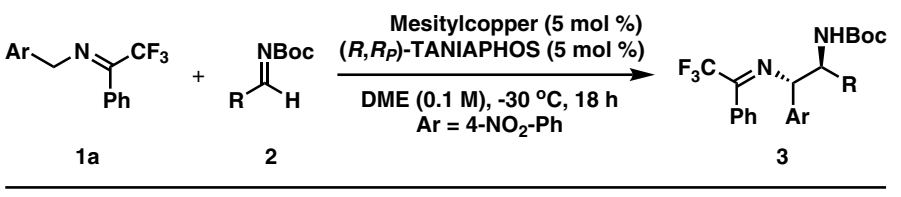

\begin{tabular}{|c|c|c|}
\hline & $\mathrm{R}=\mathrm{H}$ & 3aa, $79 \%,>20 / 1 \mathrm{dr}, 97 \%$ ee \\
\hline & $\mathrm{R}=\mathrm{Me}$ & $3 \mathrm{ab}, 80 \%,>20 / 1 \mathrm{dr}, 95 \%$ ee \\
\hline & $\mathrm{R}={ }^{t} \mathrm{Bu}$ & 3ac, $82 \%,>20 / 1 \mathrm{dr}, 97 \%$ ee \\
\hline & $\mathrm{R}=\mathrm{OMe}$ & 3ad, $86 \%,>20 / 1 \mathrm{dr}, 96 \%$ ee \\
\hline & $\mathrm{R}=$ OAllyl & 3ae, $85 \%,>20 / 1 \mathrm{dr}, 94 \%$ ee \\
\hline & $\mathrm{R}=\mathrm{OCF}_{2} \mathrm{H}$ & 3af, $74 \%,>20 / 1 \mathrm{dr}, 94 \%$ ee \\
\hline & $\mathrm{R}=\mathrm{OCH}_{2} \mathrm{CH}_{2} \mathrm{Cl}$ & 3ag, $87 \%, \quad 7 / 1 \mathrm{dr}, 94 \%$ ee \\
\hline & $\mathrm{R}=\mathrm{NMe}_{2}$ & $3 a h, 82 \%,>20 / 1 \mathrm{dr}, 96 \%$ ee \\
\hline & $\mathrm{R}=\mathrm{SMe}$ & 3ai, $72 \%,>20 / 1 \mathrm{dr}, 96 \%$ ee \\
\hline & $\mathrm{R}=$ vinyl & 3aj, $68 \%,>20 / 1 \mathrm{dr}, 95 \%$ ee \\
\hline & $\mathrm{R}=\mathrm{F}$ & 3ak, $77 \%,>20 / 1 \mathrm{dr}, 94 \%$ ee \\
\hline & $\mathrm{R}=\mathrm{Cl}$ & 3al, $49 \%,>20 / 1 \mathrm{dr}, 98 \%$ ee \\
\hline & $\mathrm{R}=\mathrm{Br}$ & 3am, $44 \%,>20 / 1 \mathrm{dr}, 81 \%$ ee \\
\hline
\end{tabular}

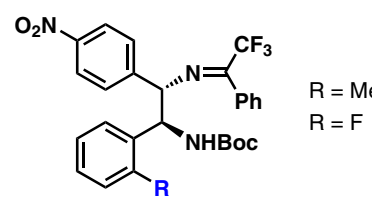

3an, $69 \%,>20 / 1 d r, 97 \%$ ee 3ao, $65 \%$, $6 / 1 \mathrm{dr}, 91 \%$ ee<smiles></smiles>

3ap, $76 \%$, >20/1 dr, $97 \%$ ee 3aq, $65 \%$, >20/1 dr, $85 \%$ ee<smiles>CC(C)(C)N[C@H](c1cccc2ccccc12)[C@@H](N=C(C(F)(F)F)[PH2+]([O-])([O-])c1ccccc1)c1ccc([N+](=O)[O-])cc1</smiles>

3ar, $75 \%, 14 / 1 \mathrm{dr}, 87 \%$ ee<smiles>CC(C)(C)OC(=O)c1ccccc1</smiles>

3au, $68 \%$, >20/1 dr, $98 \%$ ee<smiles>CC(C)[C@H](NC(=O)OCc1ccccc1)[C@H](N=C([O-])c1ccccc1)c1ccc([N+](=O)[O-])cc1</smiles>

$3 a x, 64 \%, 5 / 1 d r, 89 \%$ ee<smiles>CC(=NC(c1ccc([N+](=O)[O-])cc1)[C@H](N)c1ccc2ccccc2c1)C(F)(F)F</smiles>

$\mathrm{O}_{2} \mathrm{~N}$

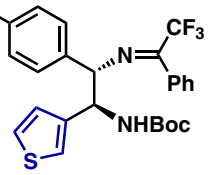

3as, $70 \%,>20 / 1$ dr, $89 \%$ ee 3 at, $80 \%, 7 / 1$ dr, $98 \%$ ee

$\mathrm{O}_{2} \mathrm{~N}$<smiles>CC(=O)OCc1ccccc1N[C@H](N=C(C(F)(F)F)C(F)(F)F)[C@H](c1ccc(I)cc1)C1CCCC1</smiles>

$\mathrm{O}_{2} \mathrm{~N}$<smiles>Nc1ccc([C@H](N=C(C(=O)OCc2ccccc2)[C@H](c2ccccc2)C2CCOCC2)C2CCOCC2)cc1</smiles>

3av, $66 \%, 5 / 1$ dr, 88\% ee $\quad$ 3aw, 70\%, 6/1 dr, 98\% ee

$\mathrm{O}_{2} \mathrm{~N}$<smiles>CC(C)C[C@H](NC(=O)OCc1ccccc1)[C@H](N=C(C(F)(F)F)C(F)(F)F)c1ccc(I)cc1</smiles>

3ay, $65 \%, 4 / 1 \mathrm{dr}, 85 \%$ ee $\mathrm{e}^{\mathrm{b}, \mathrm{c}}$

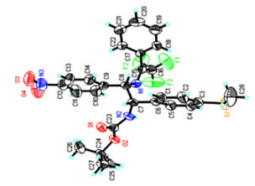

3ai, CCDC1945086

Fig. 2 Substrate scope of aldimines $\mathbf{2}^{\mathbf{a}}$. Both aromatic aldimines and aliphatic aldimines are employed. ${ }^{\mathrm{a}} \mathbf{1 a}$ : $0.2 \mathrm{mmol}, \mathbf{2}: 0.3 \mathrm{mmol}$. Isolated yield. Dr determined by ${ }^{1} \mathrm{H}$ NMR analysis of the crude reaction mixture. Enantioselectivity determined by chiral-stationary-phase HPLC analysis. ${ }^{b} 4$ equiv $\mathbf{2}$. ${ }^{c}$ The reaction is performed with $10 \mathrm{~mol} \%$ mesitylcopper and $10 \mathrm{~mol} \%\left(R, R_{P}\right)$-TANIAPHOS in THF at RT for $8 \mathrm{~h}$.

accomplished by means of a powerful reaction protocol. The capture of the benzyl copper(I) species and its further application in asymmetric catalysis are currently ongoing in our laboratory.

\section{Methods}

A general procedure for aromatic aldimines. A dried $25-\mathrm{mL}$ schlenk tube equipped with a magnetic stirring bar was charged with mesitylcopper $(1.8 \mathrm{mg}$,
$0.01 \mathrm{mmol}, 5.0 \mathrm{~mol} \%)$ and ( $R, R \mathrm{p})$-TANIAPHOS (6.8 $\mathrm{mg}, 0.01 \mathrm{mmol}, 5.0 \mathrm{~mol} \%)$ in a glove box under Ar atmosphere. Anhydrous DME $(2 \mathrm{~mL})$ was added via a syringe. The mixture was stirred for $20 \mathrm{~min}$ at room temperature to give a yellow solution. The reaction mixture was cooled to $-30^{\circ} \mathrm{C}$, and benzyl imine $(0.2 \mathrm{mmol}$, 1.0 equiv) and $N$-Boc-aldimine $(0.3 \mathrm{mmol}, 1.5$ equiv) were added. The resulting reaction mixture was stirred at $-30^{\circ} \mathrm{C}$ for $18 \mathrm{~h}$. Then, the reaction mixture was purified by silica gel column chromatography (petroleum ether/ethyl acetate $=$ $12 / 1)$ to give the desired product. 


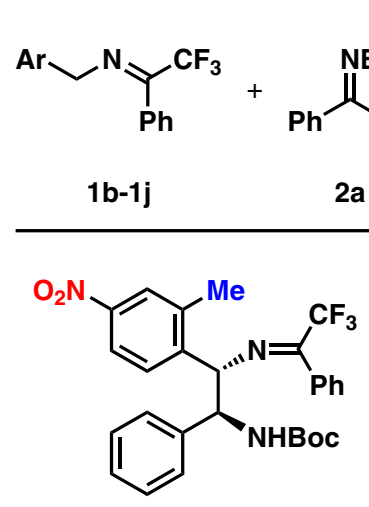

THF, $0{ }^{\circ} \mathrm{C}, 18 \mathrm{~h}$

3ba, $82 \%$, 4/1 dr, $88 \%$ ee<smiles></smiles>

THF, $-10^{\circ} \mathrm{C}, 12 \mathrm{~h}$

3ea, $76 \%$, >20/1 dr, $91 \%$ ee<smiles>CC(C)(C)OC(=O)N[C@H](c1ccccc1)[C@H](N=C(C(F)(F)F)C(F)(F)F)c1ccccc1[N+](=O)[O-]</smiles>

THF, $0^{\circ} \mathrm{C}, 12 \mathrm{~h}$ 3ha, $75 \%, 4 / 1 \mathrm{dr}, 91 \%$ ee<smiles>O=C(N[C@H](c1ccccc1)[C@H](N=C(C(F)(F)F)C(F)(F)F)c1ccc([N+](=O)[O-])cc1F)OC(=O)OCc1ccccc1</smiles>

DME, $-30{ }^{\circ} \mathrm{C}, 18 \mathrm{~h}$ 3ca, $76 \%$, >20/1 dr, $95 \%$ ee<smiles>COc1cc([C@H](N=C(c2ccccc2)C(F)(F)F)[C@H](NC(C)(C)C)c2ccccc2)ccc1[N+](=O)[O-]</smiles>

THF, $-10^{\circ} \mathrm{C}, 12 \mathrm{~h}$ 3fa, $75 \%$, >20/1 dr, $92 \%$ ee<smiles>O=C(N[C@H](c1ccccc1)[C@H](N=C([N+](=O)[O-])C(F)(F)F)c1ccc(Cl)cc1[N+](=O)[O-])OC(=O)OCc1ccccc1</smiles>

$\mathrm{THF}, 0^{\circ} \mathrm{C}, 8 \mathrm{~h}$ 3ia, $80 \%, 4 / 1$ dr, $89 \%$ ee<smiles></smiles>

THF, rt, $8 \mathrm{~h}$

3da, $78 \%$, 5/1 dr, $94 \%$ ee<smiles>CC(C)(C)OC(=O)c1ccccc1/N=C(\N[C@@H](c1ccc([N+](=O)[O-])c(SP)c1)[C@H](N=C(c1ccccc1)C(F)(F)F)c1ccccc1)c1ccccc1</smiles>

DME, $-30^{\circ} \mathrm{C}, 18 \mathrm{~h}$

3ga, $72 \%$, $>20 / 1 \mathrm{dr}, 89 \%$ ee<smiles>Cc1ccc([N+](=O)[O-])c([C@H](N=C(C(=O)OCc2ccccc2)C(F)(F)F)[C@H](N=C(c2ccccc2)c2ccccc2)c2ccccc2)c1</smiles>

THF, rt, $8 \mathrm{~h}$

3ja, $71 \%, 4 / 1$ dr, $90 \%$ ee

Fig. 3 Substrate scope of ketimines $\mathbf{1}^{\mathrm{a}}$. Ketimines derived from both 4-nitro-benzylamines and 2-nitro-benzylamines are employed. ${ }^{\mathrm{1}} \mathrm{b}$-1j: $0.2 \mathrm{mmol}$, 2a: $0.3 \mathrm{mmol}$. Isolated yield. $\mathrm{Dr}$ determined by ${ }^{1} \mathrm{H}$ NMR analysis of the crude reaction mixture. Enantioselectivity determined by chiral-stationary-phase HPLC analysis.<smiles>O=[N+]([O-])c1ccc(CN=C(c2ccccc2)C(F)(F)F)cc1</smiles><smiles>C1CCCCC1</smiles>

1a<smiles>CC(C)(C)[N+]=Cc1ccccc1</smiles>

2a

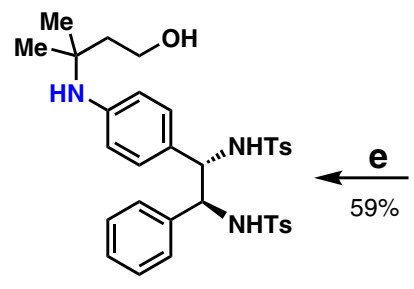

7

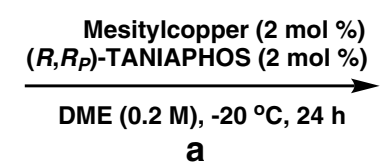

a<smiles>O=C(N[C@H](c1ccccc1)[C@H](N=C([PH2+])C(F)(F)F)c1ccccc1)c1ccccc1</smiles>

3 aa

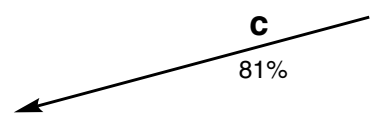

b $1.15 \mathrm{~g}, 75 \%$ $>20 / 1 \mathrm{dr}$ $96 \%$ ee

Fig. 4 Gram-scale reaction and transformations of the nitro group. a Gram-scale reaction. $\mathbf{b}$ Transformation of the nitro group to the nitrone group. Zn (6.0 equiv), $\mathrm{HOAc}\left(12.0\right.$ equiv), $\mathrm{EtOH}, \mathrm{O}^{\circ} \mathrm{C}$ to RT. c Removal of the ketimine moiety and protection of the newly generated free amine moiety. (1) $12 \mathrm{M}$

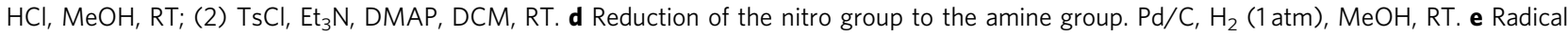
hydroamination. (1) 3-methylbut-3-en-1-ol (3.0 equiv), $\mathrm{Fe}(\mathrm{acac})_{3}(30 \mathrm{~mol} \%), \mathrm{PhSiH}_{3}, \mathrm{EtOH}, 60^{\circ} \mathrm{C}$; (2) $\mathrm{Zn}, \mathrm{HCl}, 60^{\circ} \mathrm{C}$. 
<smiles>NCCN[C@@H](c1ccc(Br)cc1)[C@H](NCCN)c1ccccc1</smiles>

10

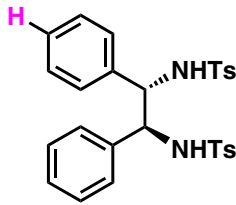

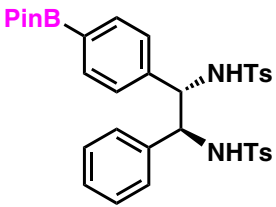

12
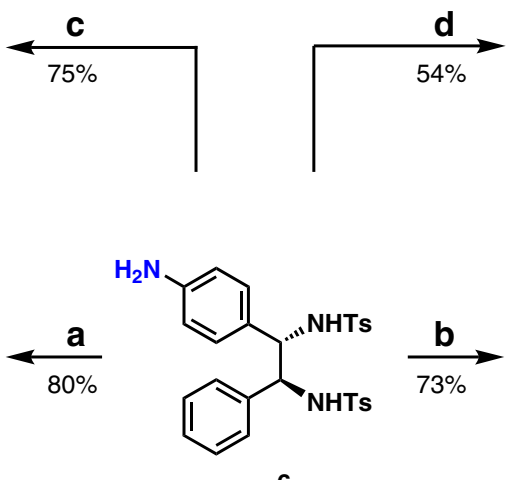

6
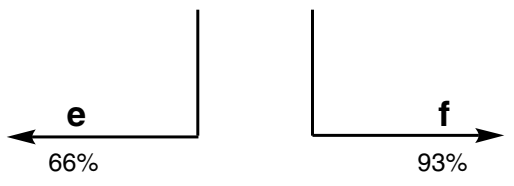<smiles>CCCCN[C@H](c1ccccc1)[C@@H](NCCN)c1ccc(C(F)(F)F)cc1</smiles>

11<smiles>CN[C@H](c1ccccc1)c1ccc(O)cc1</smiles>

9

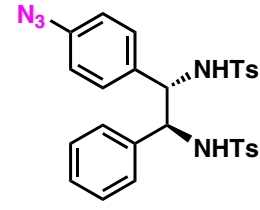

13

Fig. 5 Synthetic applications. a Removal of the amine moiety. $\mathrm{NaNO}_{2}, \mathrm{HCl}, \mathrm{H}_{3} \mathrm{PO}_{2}, \mathrm{H}_{2} \mathrm{O}, \mathrm{O}^{\circ} \mathrm{C}$. $\mathbf{b}$ transformation of the arylamine to phenol. $\mathrm{NaNO}_{2}$, $\mathrm{H}_{2} \mathrm{SO}_{4}, \mathrm{H}_{2} \mathrm{O}, \mathrm{O}$ to $100^{\circ} \mathrm{C}$. c transformation of the arylamine to arylbromide. $\mathrm{CuBr}_{2}(1 \mathrm{~mol} \%),{ }^{t} \mathrm{BuONO}, \mathrm{TsOH}, \mathrm{TBAB}, \mathrm{MeCN}, \mathrm{RT}$. d transformation of the arylamine to trifluoromethyl arene. ${ }^{t} \mathrm{BuONO}, \mathrm{HCl}, \mathrm{AgCF}_{3}, \mathrm{MeCN},-40^{\circ} \mathrm{C}$. e Transformation of the arylamine to arylBPin. ${ }^{\mathrm{t}} \mathrm{BuONO}, \mathrm{B}_{2} \mathrm{Pin}_{2}, \mathrm{MeCN}, 80{ }^{\circ} \mathrm{C}$. f Transformation of the arylamine to aryl azide. $\mathrm{KHCO}_{3}, \mathrm{FSO}_{2} \mathrm{~N}_{3}, \mathrm{MTBE} / \mathrm{DMF} / \mathrm{H}_{2} \mathrm{O}, \mathrm{RT}$.

A general procedure for aliphatic aldimines. A dried $25-\mathrm{mL}$ schlenk tube equipped with a magnetic stirring bar was charged with mesitylcopper $(3.6 \mathrm{mg}$, $0.02 \mathrm{mmol}, 10 \mathrm{~mol} \%$ ) and $(R, R \mathrm{p})$-TANIAPHOS ( $13.6 \mathrm{mg}, 0.02 \mathrm{mmol}, 10 \mathrm{~mol} \%)$ in a glove box under Ar atmosphere. Anhydrous THF $(2 \mathrm{~mL})$ was added via a syringe. The mixture was stirred for $20 \mathrm{~min}$ at room temperature to give a yellow solution. Then benzyl imine $(0.2 \mathrm{mmol}, 1.0$ equiv) and $N$-Boc-aldimine $(0.8 \mathrm{mmol}$, 4.0 equiv) were added. The resulting reaction mixture was stirred at room temperature for $8 \mathrm{~h}$. Then, the reaction mixture was purified by silica gel column chromatography (petroleum ether/ethyl acetate $=12 / 1$ ) to give the desired product.

\section{Data availability}

The X-ray crystallographic coordinates for structures reported in this study have been deposited at the Cambridge Crystallographic Data Centre (CCDC), under deposition number CCDC 1945086 (3ai) [www.ccdc.cam.ac.uk/data_request/cif]. The data supporting the findings of this study are available within the article and its Supplementary Information file. Any further relevant data are available from the authors on request.

Received: 24 January 2020; Accepted: 11 August 2020; Published online: 08 September 2020

\section{References}

1. Lucet, D., Le Gall, T. \& Mioskowski, C. The chemistry of vicinal diamines. Angew. Chem. Int. Ed. 37, 2580-2627 (1998).

2. Saibabu Kotti, S. R., Timmons, C. \& Li, G. Vicinal diamino functionalities as privileged structural elements in biologically active compounds and exploitation of their synthetic chemistry. Chem. Biol. Drug Des. 67, 101-114 (2006).

3. Lin, G.-Q., Xu, M.-H., Zhong, Y.-W. \& Sun, X.-W. An advance on exploring $\mathrm{N}$-tert-butanesulfinyl imines in asymmetric synthesis of chiral amines. Acc. Chem. Res. 41, 831-840 (2008).

4. Zhu, Y., Cornwall, R. G., Du, H., Zhao, B. \& Shi, Y. Catalytic diamination of olefins via N-N bond activation. Acc. Chem. Res. 47, 3665-3678 (2014).

5. Gladiali, S. \& Alberico, E. Asymmetric transfer hydrogenation: chiral ligands and applications. Chem. Soc. Rev. 35, 226-236 (2006).

6. Ikariya, T. \& Blacker, A. J. Asymmetric transfer hydrogenation of ketones with bifunctional transition metal-based molecular catalysts. Acc. Chem. Res. 40, 1300-1308 (2007).
7. Kizirian, J.-C. Chiral tertiary diamines in asymmetric synthesis. Chem. Rev. 108, 140-205 (2008).

8. Zhang, L., Fu, N. \& Luo, S. Pushing the limits of aminocatalysis: enantioselective transformations of $\alpha$-branched $\beta$-ketocarbonyls and vinyl ketones by chiral primary amines. Acc. Chem. Res. 48, 986-997 (2015).

9. Noble, A. \& Anderson, J. C. Nitro-Mannich reaction. Chem. Rev. 113, 2887-2939 (2013).

10. Nakamura, S. et al. Enantioselective synthesis of imidazolines with quaternary stereocenters by organocatalytic reaction of $\mathrm{N}$-(heteroarenesulfonyl)imines with isocyanoacetates. Org. Lett. 14, 2960-2963 (2012).

11. Ortín, I. \& Dixon, D. J. Direct catalytic enantio- and diastereoselective Mannich reaction of isocyanoacetates and ketimines. Angew. Chem. Int. Ed. 53, 3462-3465 (2014).

12. Hayashi, M. et al. Direct asymmetric Mannich-type reaction of $\alpha$ isocyanoacetates with ketimines using cinchona alkaloid/copper(II). catalysts. Angew. Chem. Int. Ed. 53, 8411-8415 (2014).

13. Tamura, K., Kumagai, N. \& Shibasaki, M. Direct catalytic asymmetric Mannich-type reaction of benzyl isocyanide: stereoselective synthesis of 1,2diarylethylenediamines. Eur. J. Org. Chem. 2015, 3026-3031 (2015).

14. Lu, G., Yoshino, T., Morimoto, H., Matsunaga, S. \& Shibasaki, M. Stereodivergent direct catalytic asymmetric Mannich-type reactions of $\alpha$ isothiocyanato ester with ketimines. Angew. Chem. Int. Ed. 50, 4382-4385 (2011).

15. Kato, S., Yoshino, T., Shibasaki, M., Kanai, M. \& Matsunaga, S. Catalytic asymmetric synthesis of spirooxindoles by a Mannich-type reaction of isothiocyanato oxindoles. Angew. Chem. Int. Ed. 51, 7007-7010 (2012).

16. Tang, S., Zhang, X., Sun, J., Niu, D. \& Chruma, J. J. 2-Azaallyl anions, 2azaallyl cations, 2-azaallyl radicals, and azomethine ylides. Chem. Rev. 118, 10393-10457 (2018).

17. Yan, X.-X. et al. Highly diastereoselective switchable enantioselective Mannich reaction of glycine derivatives with imines. J. Am. Chem. Soc. 130, $14362-14363$ (2008).

18. Kobayashi, S., Yazaki, R., Seki, K. \& Yamashita, Y. The fluorenone imines of glycine esters and their phosphonic acid analogues. Angew. Chem. Int. Ed. 47, 5613-5615 (2008).

19. Bandar, J. S. \& Lambert, T. H. Cyclopropenimine-catalyzed enantioselective Mannich reactions of tert-butyl glycinates with N-Boc-imines. J. Am. Chem. Soc. 135, 11799-11802 (2013)

20. Kano, T., Kobayashi, R. \& Maruoka, K. Versatile in situ generated N-Bocimines: application to phase-transfer-catalyzed asymmetric Mannich-type reactions. Angew. Chem. Int. Ed. 54, 8471-8474 (2015).

21. Chen, J. et al. Carbonyl catalysis enables a biomimetic asymmetric Mannich reaction. Science 360, 1438-1442 (2018). 
22. Lin, S., Kawato, Y., Kumagai, N. \& Shibasaki, M. Catalytic asymmetric Mannich-type reaction of $\mathrm{N}$-alkylidene- $\alpha$-aminoacetonitrile with ketimines. Angew. Chem. Int. Ed. 54, 5183-5186 (2015).

23. Kondo, M., Nishi, T., Hatanaka, T., Funahashi, Y. \& Nakamura, S. Catalytic enantioselective reaction of $a$-aminoacetonitriles using chiral bis(imidazoline) palladium catalysts. Angew. Chem. Int. Ed. 54, 8198-8202 (2015).

24. Momo, R. D., Fini, F., Bernardi, L. \& Ricci, A. Asymmetric synthesis of $\alpha, \beta-$ diaminophosphonic acid derivatives with a catalytic enantioselective Mannich reaction. Adv. Synth. Catal. 351, 2283-2287 (2009).

25. Chen, Y.-J., Seki, K., Yamashita, Y. \& Kobayashi, S. Catalytic carbon-carbon bond-forming reactions of aminoalkane derivatives with imines. J. Am. Chem. Soc. 132, 3244-3245 (2010).

26. Reddy, L. R. et al. Umpolung synthesis of vicinal diamines: diastereoselective addition of 2-azaallyl anions to Davis-Ellman's imines. Org. Lett. 20, 5423-5426 (2018).

27. Shao, X., Li, K. \& Malcolmson, S. J. Enantioselective synthesis of anti-1,2diamines by $\mathrm{Cu}$-catalyzed reductive couplings of azadienes with aldimines and ketimines. J. Am. Chem. Soc. 140, $7083-7087$ (2018).

28. Waser, M. \& Novacek, J. An organocatalytic biomimetic strategy paves the way for the asymmetric umpolung of imines. Angew. Chem. Int. Ed. 54, 14228-14231 (2015).

29. Wu, Y., Hu, L., Li, Z. \& Deng, L. Catalytic asymmetric umpolung reactions of imines. Nature 523, 445-450 (2015).

30. Hu, L., Wu, Y., Li, Z. \& Deng, L. Catalytic asymmetric synthesis of chiral $\gamma$ amino ketones via umpolung reactions of imines. J. Am. Chem. Soc. 138, 15817-15820 (2016).

31. $\mathrm{Hu}, \mathrm{B}$. et al. Origin of and a solution for uneven efficiency by cinchona alkaloid-derived, pseudoenantiomeric catalysts for asymmetric reactions. J. Am. Chem. Soc. 140, 13913-13920 (2018).

32. Hu, B. \& Deng, L. Catalytic asymmetric synthesis of trifluoromethylated $\gamma$ amino acids through the umpolung addition of trifluoromethyl imines to carboxylic acid derivatives. Angew. Chem. Int. Ed. 57, 2233-2237 (2018).

33. Li, Z., Hu, B., Wu, Y., Fei, C. \& Deng, L. Control of chemoselectivity in asymmetric tandem reactions: direct synthesis of chiral amines bearing nonadjacent stereocenters. Proc. Nat. Acad. Sci. USA 115, 1730-1735 (2018).

34. Hu, B. \& Deng, L. Direct catalytic asymmetric synthesis of trifluoromethylated $\gamma$-amino esters/lactones via umpolung strategy. J. Org. Chem. 84, 994-1005 (2019).

35. Guo, C., Song, J. \& Gong, L.-Z. Biomimetic asymmetric 1,3-dioplar cycloaddition: amino acid precursors in biosynthesis serve as latent azomethine ylides. Org. Lett. 15, 2676-2679 (2013).

36. Tian, L., Hu, X.-Q., Li, Y.-H. \& Xu, P.-F. Organocatalytic asymmetric multicomponent cascade reaction via 1,3-proton shift and [3+2] cycloaddition: an efficient strategy for the synthesis of oxindole derivatives. Chem. Commun. 49, 7213-7215 (2013).

37. Yoshida, Y., Mino, T. \& Sakamoto, M. Organocatalytic highly regio- and enantioselective umpolung Michael addition reaction of a-imino esters. Chem. Eur. J. 23, 12749-12753 (2017).

38. Yoshida, Y., Moriya, Y., Mino, T. \& Sakamoto, M. Regio-and enantioselective synthesis of $\alpha$-amino- $\delta$-ketoesters through catalytic umpolung reaction of $\alpha$ iminoesters with enones. Adv. Synth. Catal. 360, 4142-4146 (2018).

39. Yoshida, Y., Omori, K., Hiroshige, T., Mino, T. \& Sakamoto, M. Chemoselective catalytic asymmetric synthesis of functionalized aminals through the umpolung organocascade reaction of a-imino amides. Chem. Asian J. 14, 2737-2743 (2019).

40. Ono, N. The Nitro group in Organic Synthesis (Wiley-VCH, 2001).

41. Mo, F., Qiu, D., Zhang, Y. \& Wang, J. Renaissance of Sandmeyer-type reactions: conversion of aromatic $\mathrm{C}-\mathrm{N}$ bonds into $\mathrm{C}-\mathrm{X}$ bonds $(\mathrm{X}=\mathrm{B}, \mathrm{Sn}, \mathrm{P}$, or $\mathrm{CF}_{3}$ ). Acc. Chem. Res. 51, 496-506 (2018).

42. Stollenz, M. \& Meyer, F. Mesitylcopper-a powerful tool in synthetic chemistry. Organometallics 31, 7708-7727 (2012).
43. Matias, A. C., Biazolla, G., Cerchiaro, G. \& Keppler, A. F. a-Aryl-N-aryl nitrones: synthesis and screening of a new scaffold for cellular protection against an oxidative toxic stimulus. Bioorg. Med. Chem. 24, 232--2239 (2016).

44. Gui, J. et al. Practical olefin hydroamination with nitroarenes. Science 348, 886-891 (2015)

45. Wang, X. et al. Silver-mediated trifluoromethylation of aryldiazonium salts: conversion of amino group into trifluoromethyl group. J. Am. Chem. Soc. 135, 10330-10333 (2013).

46. Qiu, D. et al. Synthesis of pinacol arylboronates from aromatic amines: a metal-free transformation. J. Org. Chem. 78, 1923-1933 (2013).

47. Meng, G. et al. Modular click chemistry libraries for functional screens using a diazotizing reagent. Nature 574, 86-89 (2019).

\section{Acknowledgements}

We gratefully acknowledge the financial support from the National Natural Science Foundation of China (Nos. 21672235, 21871287, and 21922114), the Strategic Priority Research Program of the Chinese Academy of Sciences (No. XDB20000000), the Shanghai Municipal Education Commission (2019-01-07-00-10-E00072), CAS Key Laboratory of Synthetic Chemistry of Natural Substances, and Shanghai Institute of Organic Chemistry.

\section{Author contributions}

L.Y. and P.T. conceived and designed the study. X.C.G. and C.Y.Z. performed the synthetic experiments and analyzed the data for all new compounds. L.Y. wrote the paper. C.Y.Z. and F.Z. did the required revisions.

\section{Competing interests}

The authors declare no competing interests.

\section{Additional information}

Supplementary information is available for this paper at https://doi.org/10.1038/s41467020-18235-9.

Correspondence and requests for materials should be addressed to P.T. or L.Y.

Peer review information Nature Communications thanks the anonymous reviewer(s) for their contribution to the peer review of this work.

Reprints and permission information is available at http://www.nature.com/reprints

Publisher's note Springer Nature remains neutral with regard to jurisdictional claims in published maps and institutional affiliations.

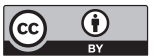

Open Access This article is licensed under a Creative Commons Attribution 4.0 International License, which permits use, sharing adaptation, distribution and reproduction in any medium or format, as long as you give appropriate credit to the original author(s) and the source, provide a link to the Creative Commons license, and indicate if changes were made. The images or other third party material in this article are included in the article's Creative Commons license, unless indicated otherwise in a credit line to the material. If material is not included in the article's Creative Commons license and your intended use is not permitted by statutory regulation or exceeds the permitted use, you will need to obtain permission directly from the copyright holder. To view a copy of this license, visit http://creativecommons.org/ licenses/by/4.0/.

(C) The Author(s) 2020 